\title{
Studi persepsi pengunjung pada Taman Janggan, Denpasar
}

\author{
I Gde Andre Aldiguna ${ }^{1}$, Cokorda Gede Alit Semarajaya ${ }^{1 *}$, Ida Ayu Mayun ${ }^{2}$
}

1. Prodi Arsitektur Pertamanan, Fakultas Pertanian, Universitas Udayana, Indonesia 80236

2. Prodi Agroekoteknologi, Fakultas Pertanian, Universitas Udayana, Indonesia 80236

*Email: coksemarajaya@unud.ac.id

\begin{abstract}
Study of user perception in Janggan Park, Denpasar. Janggan Park is a park located in Denpasar City with designed like the janggan kite which was inaugurated on January 5, 2017 by the Vice Governor of Bali. Janggan park there is also a children's play ground and gym facilities. The purpose of this study is to measure the visitor's perception of the beauty, comfort, and safety of Janggan Park in Denpasar and to provide some input to the manager or agency concerned in order to improve the quality of the site. The method used in this research was direct observation to the field, interview, and questionnaire. Based on the research conducted, the results showed that the perception of visitors about the beauty of Janggan Park was beautiful, but there are some part in the garden were less beautiful, that is gym area. The visitor's perception of comfort at Janggan Park was comfortable. Then, the visitor's perception about the secure at Janggan Park was safe. According to the visitor perception of cleanliness at Janggan Park still less clean and need more attention on maintenance because cleanliness also influence the beauty, comfort, and visitor safety. It can be suggested that the manager need to improve the hygiene, supervision, and to improve exsisting facility in Janggan Park.
\end{abstract}

Keywords: aesthetic, comfort, green open space, safety

\section{Pendahuluan}

Denpasar memiliki taman kota yang diberi nama Taman Janggan yang terletak di Jl. Raya Puputan, Kelurahan Sumerta Kelod, Kecamatan Denpasar Timur. Menurut asisten perencanaan Satuan Kerja Penataan Bangunan dan Lingkungan Provinsi Bali, penamaan Taman Janggan diberikan oleh Wakil Gubernur Bali terinspirasi dari layangan janggan (Gambar 1). Area bermain anak pada bagian timur taman diibaratkan sebagai kepala dan jalan setapak yang memanjang diibaratkan sebagai ekor dari layangan janggan. Desain tersebut merupakan hasil desain dari konsultan, tim teknisi Penataan Bangunan dan Lingkungan serta masukan dari Gubernur dan Wakil Gubernur (Sudiasa, 2018).

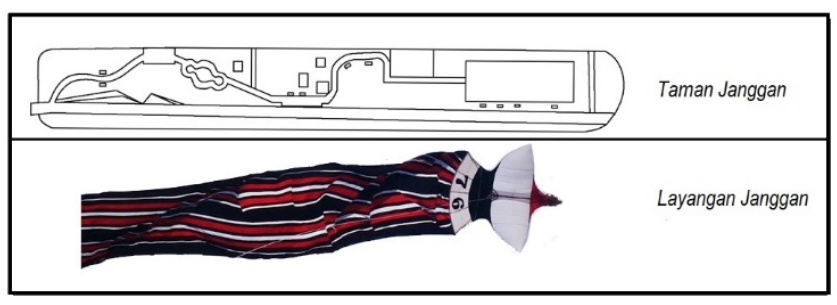

Gambar 1. Penamaan Taman Janggan yang Terinspirasi Dari Layangan Janggan

Pada Taman Janggan selain untuk tempat beristirahat, terdapat juga area bermain anak-anak yang dapat digunakan sebagai pendekatan anak dengan lingkungan sekitarnya. Terdapat juga sarana berolahraga yang bisa digunakan oleh pengunjung. Taman yang tergolong baru ini tentunya memiliki kelebihan maupun kekurangan. Sebagai ruang publik perlu memperhatikan keindahan, kenyamanan, dan keamanan karena ketiga hal tersebut mempengaruhi tingkat kesenangan pengunjung (Pradipta, 2018). Hal tersebut yang melatarbelakangi penulis untuk mengangkat permasalahan bagaimana persepsi pengunjung terhadap keindahan, kenyamanan, dan keamanan pada Taman Janggan yang bertujuan untuk meningkatkan kualitas Taman Janggan agar menjadi pilihan bagi para pengunjung untuk dapat menikmati fasilitas yang ada. 


\section{Metode}

Penelitian ini dilakukan di Taman Janggan Denpasar, yang berada di Jl. Raya Puputan, Kelurahan Sumerta Kelod, Kecamatan Denpasar Timur (Gambar 2.). Waktu yang dibutuhkan dalam penelitian yakni selama sebelas bulan yang dimulai pada bulan Juli 2017 sampai Juni 2018.

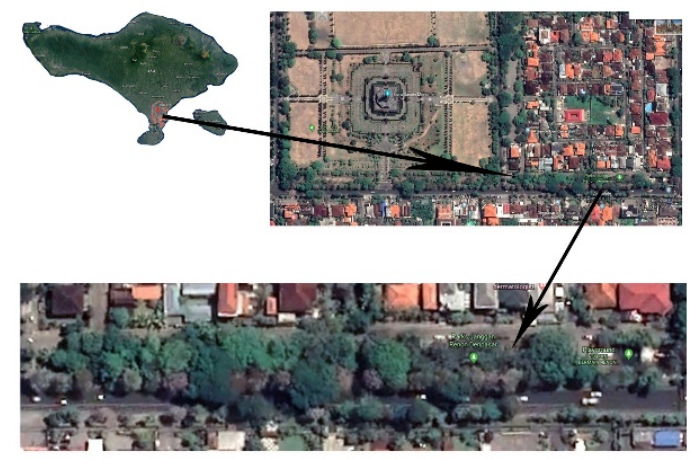

Gambar 2. Lokasi Penelitian

Alat yang digunakan dalam penelitian ini meliputi alat tulis, kamera, perekam suara, alat ukur serta perangkat komputer/laptop yang digunakan untuk mengolah data berupa Adobe Photoshop dan Microsoft Office. Bahan yang dipergunakan dalam penelitian ini adalah lembar kuisioner dan pertanyaan wawancara. Metode penelitian yang digunakan adalah metode survey. Data dikumpulkan berupa data primer melalui observasi dilapangan, wawancara langsung, kuisioner dan data sekunder berupa studi pustaka. Teknik yang digunakan adalah purposive sampling, yakni teknik penentuan sampel yang sengaja dipilih peneliti berdasarkan pertimbangan tujuan penelitian melalui pertanyaan yang diajukan mengenai persepsi masyarakat terhadap Taman Janggan. Metode analisis data meliputi tahap pengolahan data hasil observasi, kuisioner, dan wawancara. Metode yang digunakan adalah tabulasi, pembobotan, dan analisis deskriptif (Silalahi, 2006). Pembobotan menggunakan skala Likert dengan hasil 1,00-1,80= Tidak indah/nyaman/aman; 1,81-2,60= Kurang indah/nyaman/aman; 2,61-3,40= Cukup indah/nyaman/aman; 3,41-4.20= Indah/nyaman/aman; 4,21$5,00=$ Sangat indah/nyaman/aman (Sugiyono, 2017).

Setelah dilakukan analisis terhadap data hasil observasi, kuisioner dan wawancara, selanjutnya akan dilakukan tahap sintesis. Sintesis merupakan tahapan pemecahan masalah dari objek penelitian berdasarkan hasil analisis data dengan metode tabulasi dan analisis deskriptif.

Lokasi penelitian dibatasi hanya pada bagian timur di area bermain anak dan outdoor gym Taman Janggan. Batasan ini dilakukan karena pengunjung yang datang lebih banyak melakukan aktivitas dan kegiatan pada area tersebut. Penelitian dibatasi pada persepsi masyarakat terhadap keindahan, kenyamanan, dan keamanan Taman Janggan.

\section{Hasil dan Pembahasan}

\subsection{Kondisi Umum Taman Janggan Denpasar}

Taman Janggan terletak di kawasan Renon, tepat sebelah timur Taman Kota Niti Mandala Renon, disebelah barat bundaran renon dan Plaza Renon. Gambaran umum dari kondisi Taman Janggan dapat dilihat pada Gambar 3. Taman Janggan dibangun pada lahan seluas $4.425 \mathrm{~m}^{2}$ yang dimanfaatkan untuk menjadi ruang terbuka hijau ditengah padatnya Kota Denpasar dan diresmikan pada tanggal 5 Januari 2017 (Tribun Bali, 2017). Berdasarkan hasil observasi yang dilakukan di lapang, Taman Janggan memiliki tiga atraksi utama, yaitu area bermain anak, sarana olahraga, jalan setapak disertai bangku taman.

Area playground memiliki luas $304 \mathrm{~m}^{2}$ yang terletak di bagian timur Taman Janggan. Aktivitas yang dapat dilakukan pada area ini adalah bermain. Pada area outdoor gym aktivitas yang dapat dilakukan yaitu berolahraga, memiliki berbagai macam fasilitas kebugaran seperti pro cycle dan space walker (sejenis alat untuk berjalan/berlari ditempat), sit up bench (sandaran/sarana untuk sit up), dan rowing machine (sejenis alat dengan gerakan mendayung). Jalan setapak merupakan jalan penghubung antara area parkir dengan area gym dan area playground. Disepanjang jalan setapak pada titik tertentu terdapat bangku taman yang bisa dimanfaatkan pengunjung untuk beristirahat. Fasilitas parkir Taman Janggan terletak disebelah utara taman dengan memanfaatkan pinggiran jalan kecil di wilayah tersebut. 


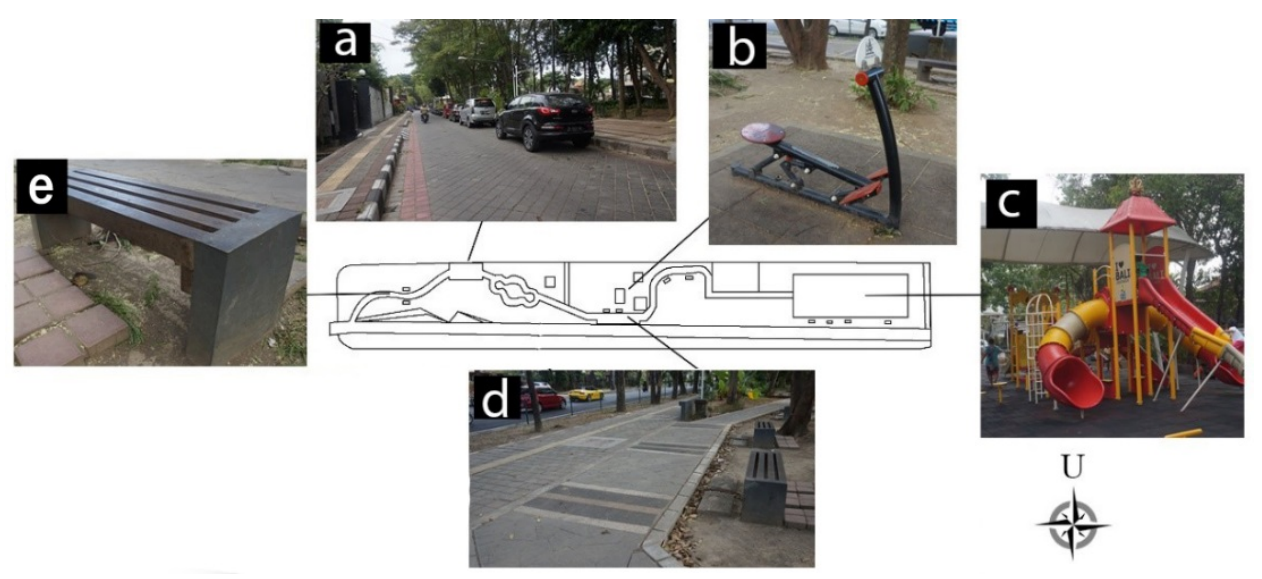

Gambar 3. Gambaran Umum Kondisi Taman Janggan.

Keterangan: (a) Area parkir; (b) Fasilitas gym; (c) Area bermain; (d) Jalan setapak; (e) Fasilitas kursi taman

\subsection{Latar Belakang Responden Taman Janggan Denpasar}

Berdasarkan hasil penelitian, responden pengunjung Taman Janggan Denpasar terdiri dari 50\% orang laki-laki dan $50 \%$ orang perempuan. Berdasarkan umur responden dikelompokkan menjadi tiga kelompok. Kelompok umur 17-25 tahun sebanyak 36,7\% dari total responden, umur 26-35 tahun sebanyak $43,3 \%$, umur 36-45 tahun sebanyak 20\%

Berdasarkan survei di lapangan, latar belakang pendidikan terakhir responden Taman Janggan paling banyak berasal dari tingkat pendidikan SMA atau sederajat yaitu sebanyak $46,7 \%$ kemudian berasal dari tingkat pendidikan Perguruan Tinggi sebanyak $36,7 \%$, SMP sebanyak $13,3 \%$, dan tidak bersekolah sebanyak $3,3 \%$. Pengunjung yang berkunjung ke Taman Janggan Denpasar didominasi oleh pegawai swasta sebanyak $40 \%$ dan siswa/mahasiswa sebanyak $23.3 \%$. Hasil kuisioner mengenai latar belakang responden dapat disimpulkan, bahwa yang mendominasi kunjungan pada Taman Janggan Denpasar merupakan kalangan anak muda dan keluarga.

\subsection{Kunjungan dan Aktivitas Responden di Taman Janggan}

\subsubsection{Frekuensi Kunjungan}

Hasil penelitian yang diperoleh mengenai frekuensi kunjungan sudah berapa kali pengunjung melakukan kunjungan ke Taman Janggan menyatakan tidak tentu dalam seminggu sebanyak 36,7\%, jarang (1-3 kali) sebanyak 30\%, sangat jarang (sekali dalam seminggu) sebanyak $26,7 \%$ dan sering (3-5 kali dalam seminggu) sebanyak $6,7 \%$.

\subsubsection{Sumber Informasi}

Pengunjung mengetahui informasi mengenai keberadaan tapak berasal dari berbagai sumber. Sebagian besar pengunjung memperoleh informasi melalui teman (56,7\%), dari keluarga sebanyak $23,3 \%$, media elektronik seperti televisi dan radio sebanyak $10 \%$, melalui internet seperti sosial media sebanyak $6,7 \%$ dan media cetak seperti koran sebanyak 3,3\%.

\subsubsection{Waktu Kunjungan}

Waktu kunjungan pengunjung pada Taman Janggan Denpasar dibagi menjadi empat waktu yaitu pagi, siang, sore, dan malam hari. Pengunjung terbanyak yakni pada saat sore hari sebanyak $86,7 \%$ dan pada pagi hari sebanyak $13,3 \%$, itu dikarenakan pada pagi maupun sore hari merupakan saat yang tepat untuk berinteraksi dengan lingkungan sebelum maupun setelah melakukan kegiatan seharian seperti bekerja, dan sekolah.

\subsubsection{Aktivitas Responden di Taman Janggan Denpasar}

Berdasarkan hasil penelitian sebagian besar pengunjung melakukan aktivitas jalan-jalan dan bermain (80\%), itu dikarenakan pada Taman Janggan terdapat area bermain anak yang dapat dimanfaatkan oleh anakanak untuk bermain dan tentunya diawasi para orang tua. Kemudian pengunjung yang melakukan aktivitas berkumpul/bersosialisasi ada sebanyak $10 \%$. Sebanyak $10 \%$ pengunjung yang datang juga memanfaatkan taman sebagai tempat untuk menikmati pemandangan. 


\subsection{Persepsi Pengunjung Taman Janggan Denpasar}

\subsubsection{Keindahan pada Taman Janggan}

Aquinas dalam Gie (1983) menyatakan keindahan sama dengan sesuatu yang menyenangkan. Keindahan yang dimaksud adalah keindahan secara universal menurut pengamatan dari pengunjung mulai dari softscape dan hardscape. Pada Gambar 4 dapat dilihat persepsi pengunjung mengenai Taman Janggan. Secara garis besar, pengunjung menyatakan Taman Janggan sudah cukup indah untuk menjadi ruang terbuka hijau.

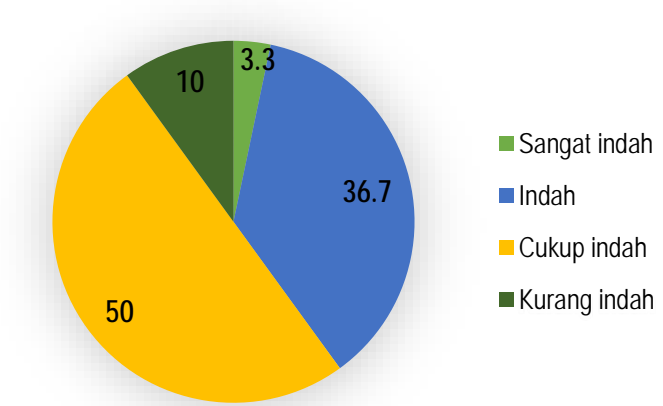

Gambar a. Persepsi pengunjung mengenai keindahan Taman Janggan.

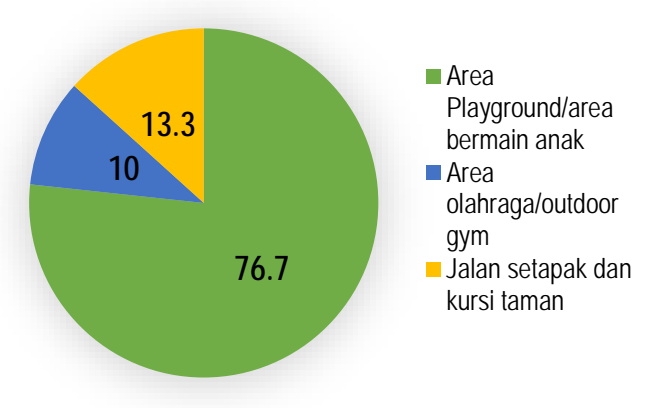

Gambar c. Bagian pada taman yang paling indah
3.3

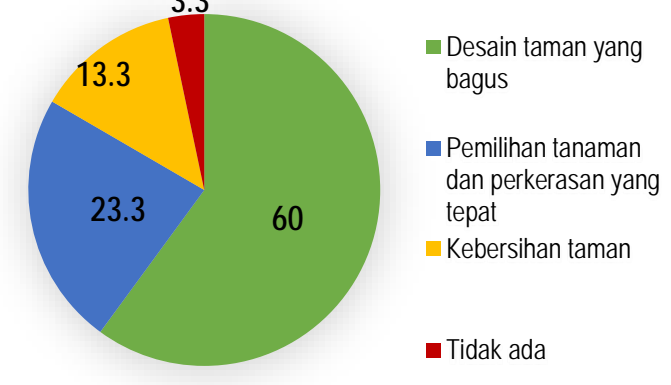

Gambar b. Faktor yang menyebabkan Taman Janggan dapat dikatakan indah

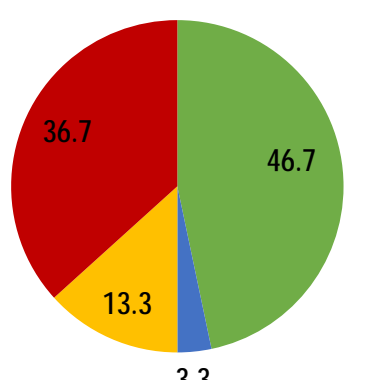

3.3
Menarik secara visual

- Mampu memberikan kenangan

Memiliki ciri khas

- Penataan dan penempatan yang baik
Gambar d. Keindahan pada masingmasing bagian taman

Gambar 4. Persepsi pengunjung mengenai Taman Janggan

Ada beberapa faktor yang menyebabkan Taman Janggan dapat dikatakan indah, salah satunya yang paling berpengaruh menurut responden adalah desain taman yang bagus (Gambar 5.) Pada Taman Janggan $76,7 \%$ responden menyatakan area playground/area bermain anak merupakan tempat yang paling indah. Karena area tersebut yang paling menonjol dan memberikan atraksi kepada para pengunjung. Kemudian pada Gambar 7, responden menyatakan kenapa mereka memilih bagian taman yang mereka pilih sebagai tempat yang paling indah karena menarik secara visual (46,7\%), kemudian $36,7 \%$ responden menyatakan penataan dan penempatan ornament yang baik mampu memberikan kesan indah kepada para responden yang datang. Keindahan Taman Janggan seperti keindahan warna, bentuk, keanekaragaman jenis, dan keindahan penataan pada masing-masing wahana/fasilitas yang ada, keindahan jenis tanaman dan perpaduan warna pada area gym, dan keindahan bentuk dan motif bangku taman dan jalan setapak menurut responden sudah cukup indah, dapat dilihat pada Gambar 5. 


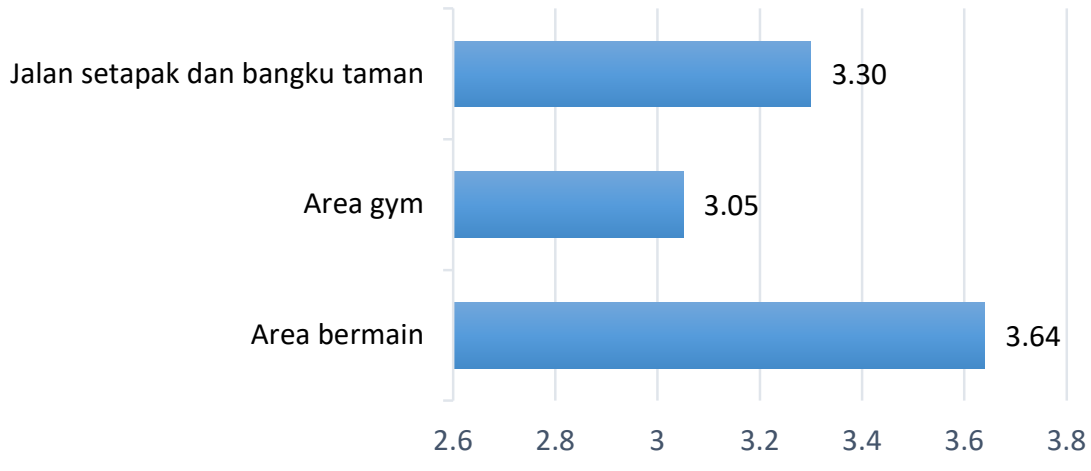

Gambar 5. Keindahan fasilitas yang ada pada Taman Janggan.

Taman Janggan sudah cukup indah menurut data hasil kuesioner yang dilakukan. Namun tentu saja ada hal yang membuat taman tersebut kurang indah. Pada Gambar 9, dari hasil kuesioner yang dilakukan sebanyak 76,7\% responden menyatakan yang menyebabkan Taman Janggan kurang indah adalah kurangnya kebersihan. Perlu ditingkatkan kebersihan pada tapak dengan cara menambahkan tempat sampah di titik strategis seperti area bermain anak. Selain itu penambahan petugas kebersihan dapat menjadi alternatif agar kebersihan taman tetap terjaga.

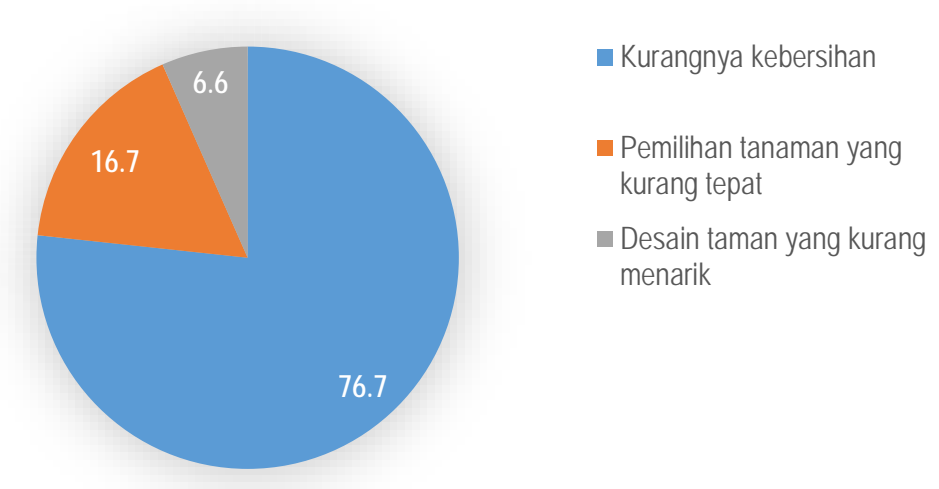

Gambar 9. Faktor yang menyebabkan Taman Janggan terlihat kurang indah.

\subsubsection{Kenyamanan pada Taman Janggan}

Responden mempunyai persepsi masing-masing mengenai kenyamanan yang dirasakan saat berkunjung ke Taman Janggan. Dapat dilihat pada Gambar 6, 93,3\% responden menyatakan bahwa Taman Janggan sudah cukup nyaman - sangat nyaman. Manusia menilai kondisi lingkungan berdasarkan rangsangan yang masuk ke dalam dirinya. Dalam hal ini yang terlibat tidak hanya masalah fisik biologis, namun juga perasaan, suara, cahaya, aroma, dan suhu rangsangan ditangkap sekaligus, lalu diolah oleh otak, kemudian otak akan memberikan penilaian relatif apakah kondisi itu nyaman atau tidak (Satwiko, 2009).

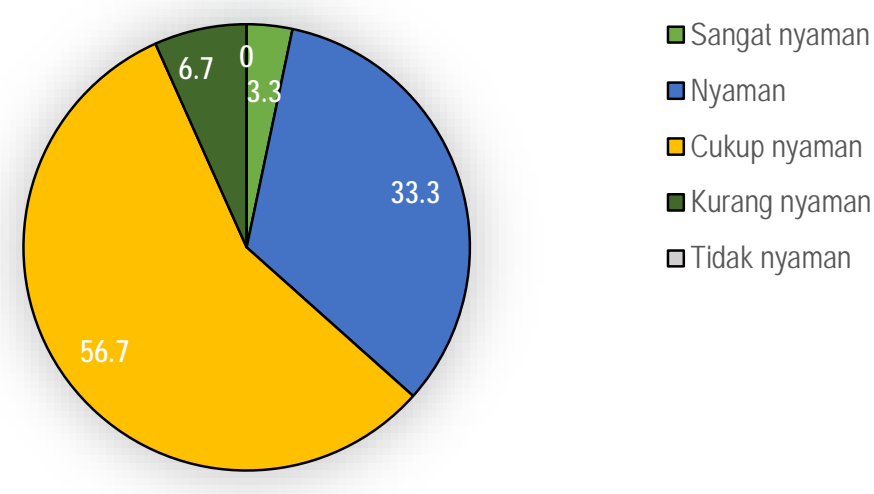

Gambar 6. Kenyamanan pada Taman Janggan. 
Sebanyak $76,7 \%$ responden menyatakan faktor yang membuat Taman Janggan terasa nyaman adalah lokasi yang teduh/rindang. Taman yang teduh dengan banyak jenis pohon tinggi besar dapat membuat suasana terasa sejuk dan dapat menghasilkan oksigen lebih banyak. Selain itu $10 \%$ responden menyatakan kebersihan menyebabkan Taman Janggan terasa nyaman. 10\% lainnya menyatakan penataan taman yang rapi dan 3,3\% menyatakan fasilitas yang memadai membuat Taman Janggan terasa nyaman.

Kemudian kenyamanan material pada wahana area bermain anak, material pada masing-masing sarana outdoor gym, dan fasilitas lainnya seperti bangku taman dan jalan setapak, serta kenyamanan mengenai paparan sinar matahari rata-rata responden menyatakan nyaman. Hasil dari kenyamanan responden pada Taman Janggan dapat dilihat pada Gambar 7.

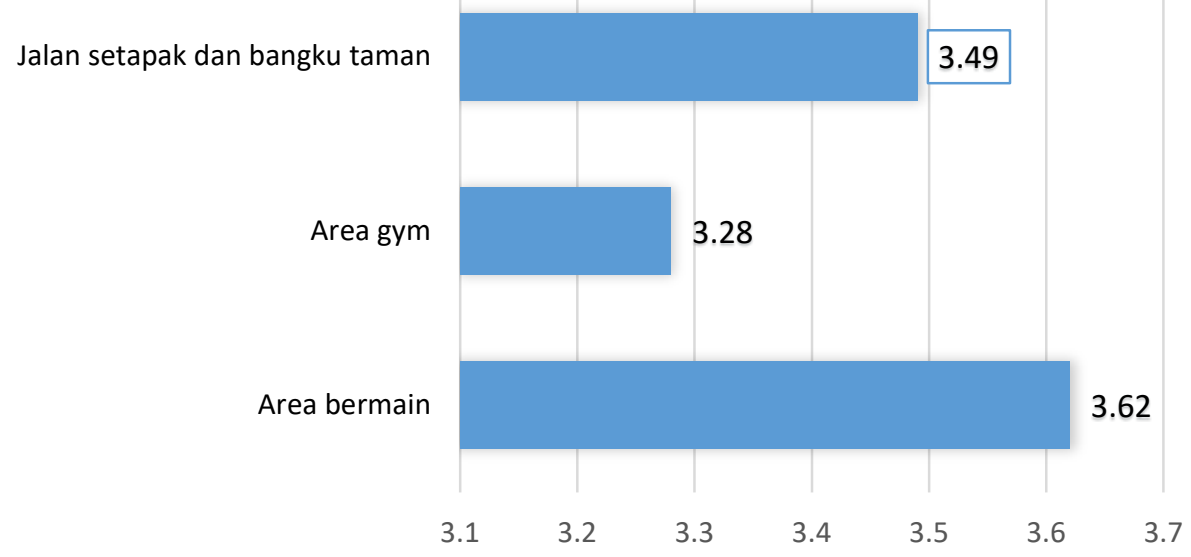

Gambar 7. Kenyamanan fasilitas yang ada pada Taman Janggan.

Ada beberapa penyebab Taman Janggan dapat dikatakan kurang nyaman, 46,7\% responden menyatakan bahwa area Taman Janggan kotor. Sampah plastik berserakan hampir diseluruh area meskipun sudah disediakan tempat sampah. 36,7\% responden juga menyatakan bahwa Taman Janggan kurang luas (Gambar 8).

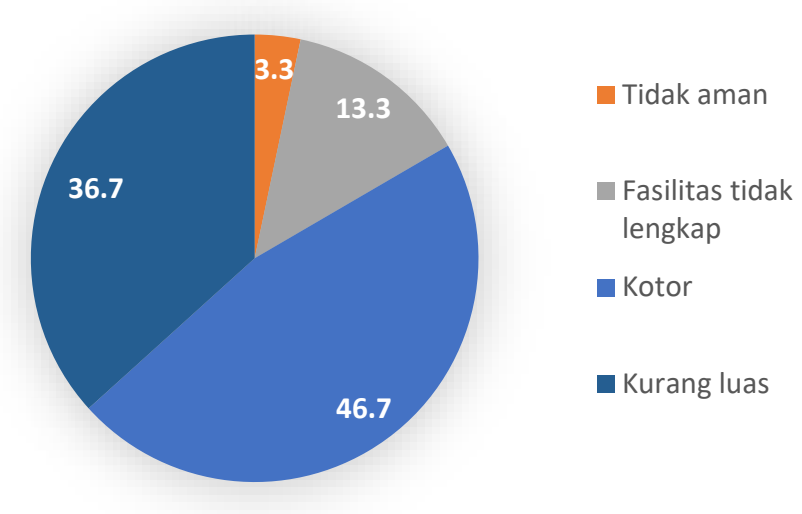

Gambar 8. Faktor penyebab Taman Janggan kurang nyaman.

\subsubsection{Keamanan pada Taman Janggan}

Menurut Hakim (2003) keamanan merupakan masalah yang penting, karena ini dapat mengganggu dan menghambat aktivitas yang dilakukan. Pengertian dari keamanan bukan saja mencakup segi kejahatan (kriminal) tapi juga termasuk kekuatan konstruksi dari elemen taman, tata letak elemen, bentuk elemen, dan kejelasan fungsi. Persepsi pengunjung mengenai keamanan pada Taman Janggan menunjukkan bahwa Taman Janggan dapat dikatakan sudah cukup aman terlihat dari hasil kuesioner pada Gambar 9. 


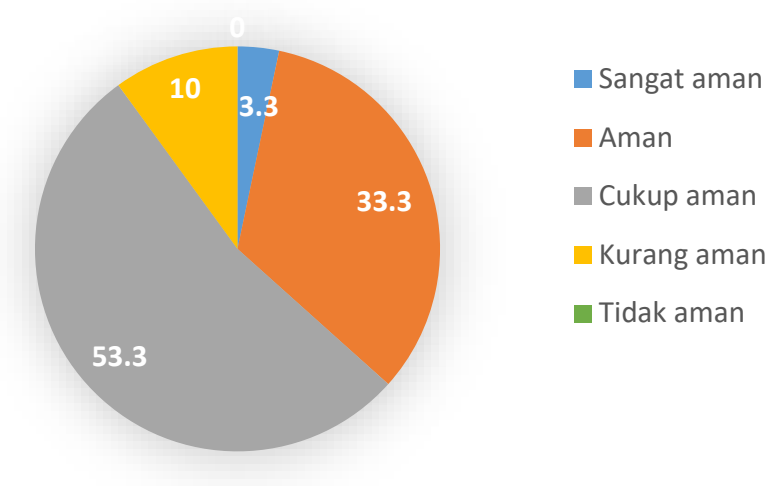

Gambar 9. Persepsi Pengunjung Mengenai Keamanan di Kawasan Taman Janggan.

Ada beberapa faktor yang membuat pengunjung merasa aman jika berkunjung ke Taman Janggan. Pada Gambar 14, 46,7\% responden menyatakan bahwa minimnya tindakan kriminalitas pada tapak menjadi faktor utama pengunjung merasa aman untuk berkunjung ke Taman Janggan. Ada juga beberapa faktor yang menyebabkan Taman Janggan cukup aman untuk dikunjungi, data dapat dilihat pada Gambar 10.

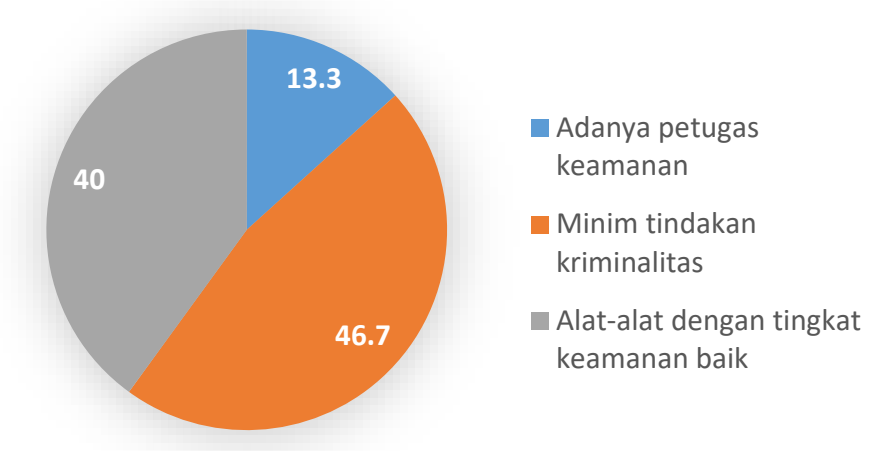

Gambar 10. Faktor Penyebab Taman Janggan Dapat Dikatakan Aman

Fasilitas yang ada pada Taman Janggan sudah aman menurut responden seperti keamanan bahan dan ketinggian fasilitas bermain, keamanan material alat-alat olahraga, dan keamanan barang berharga. Pasal 4 Undang-Undang No.8 Tahun 1999 Poin (a) dalam Sarsiti dan Taufik (2012) menerangkan tentang hak seorang konsumen bahwa: "konsumen (wisatawan) berhak atas kenyamanan dan keamanan atau keselamatan dalam mengkonsumsi barang dan/atau jasa". Salah satu contohnya adalah bahan yang digunakan sudah sangat kokoh dan baik seperti sarana olahraga dan bermain. Hasil kesimpulan kuesioner responden mengenai keamanan pada masing-masing fasilitas yang ada pada Taman Janggan dapat dilihat pada Gambar 11.

Jalan setapak dan bangku taman

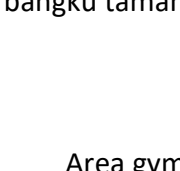

Area gym

Area bermain

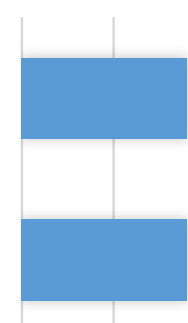

3.28

3.28

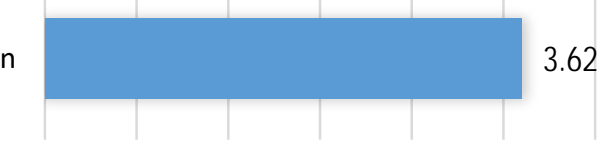

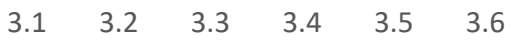

3.62

3.7

Gambar 11. Keamanan fasilitas yang ada pada Taman Janggan. 
Terdapat juga persepsi pengunjung mengenai faktor penyebab Taman Janggan dapat dikatakan tidak aman menurut pengunjung. $83,3 \%$ responden menyatakan bahwa salah satu faktor utama yang menyebabkan taman kurang aman adalah tidak adanya petugas keamanan (Gambar 12).

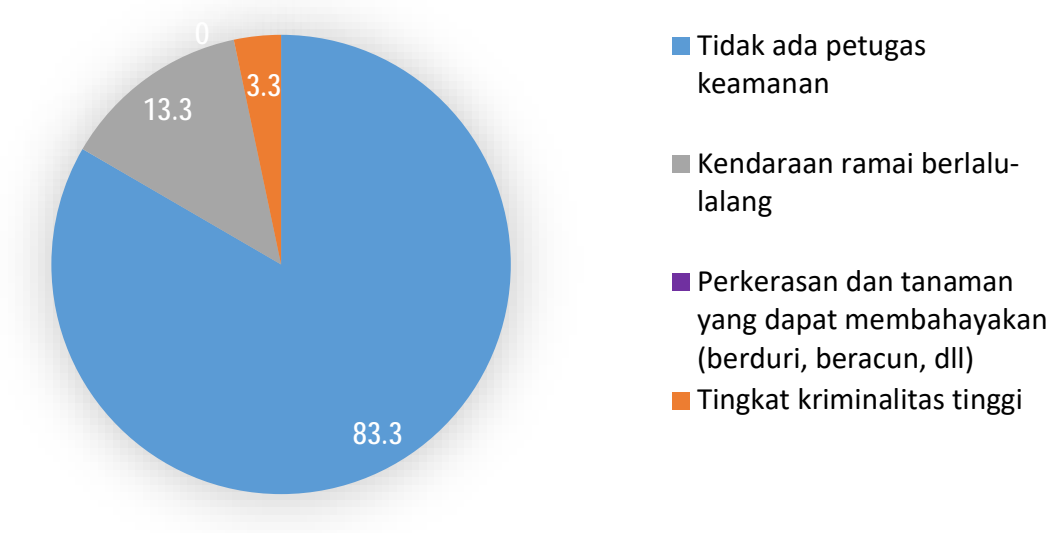

Gambar 12. Faktor penyebab Taman Janggan dapat dikatakan tidak aman menurut pengunjung

\subsubsection{Kondisi dan fasilitas yang perlu ditambahkan pada Taman Janggan}

Kondisi yang dimaksud adalah pemeliharaan, dan kebersihan pada Taman Janggan. Menurut persepsi responden, 56,7\% responden menyatakan Taman Janggan belum terpelihara dengan baik karena terdapat fasilitas olahraga yang mulai rusak dan tanaman yang belum mendapat perawatan. Sedangkan 43,3\% responden lainnya menyatakan sudah terpelihara dengan baik.

Mengenai kebersihan, dapat dilihat pada Gambar 13, rata-rata pengunjung menyatakan kurangnya kebersihan pada area bermain, outdoor gym, dan jalan setapak dan bangku taman. Hal ini disebabkan oleh sampah dari pengunjung yang ditinggalkan begitu saja tanpa ada kesadaran untuk membuang sampah pada tempatnya dan sampah yang dihasilkan oleh tanaman yang terdapat di Taman Janggan.
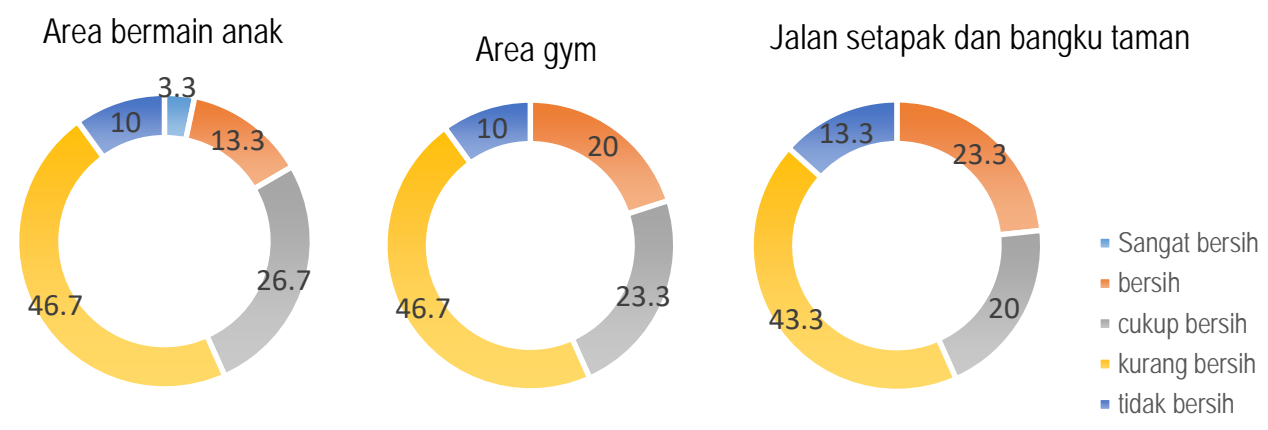

Gambar 13. Kebersihan pada Taman Janggan.

Dari hasil penelitian yang dilakukan ada beberapa elemen dan fasilitas yang perlu ditambahkan pada Taman Janggan untuk menunjang keindahan, kenyaman, dan keamanan bagi pengunjung. Sebanyak 33,3\% responden menginginkan ditambahkan bangku pada area taman. $26,7 \%$ responden menginginkan penambahan area parkir, dan $13,3 \%$ responden menginginkan penambahan tanaman dan $26,7 \%$ lainnya menginginkan penambahan lampu pada Taman Janggan. 


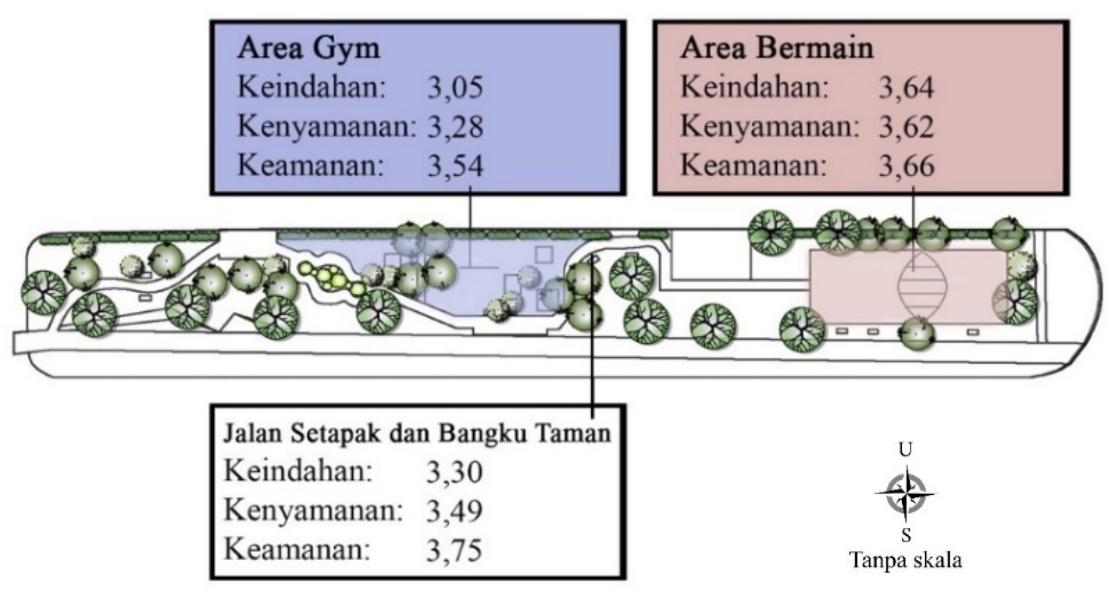

Gambar 14. Mapping dari hasil penilaian persepsi responden

Pada Gambar 14, sesuai hasil dari keseluruhan kuesioner, area bermain dinilai sudah indah, nyaman, dan aman, kemudian area gym masuk dalam kategori sudah cukup indah, cukup nyaman, dan aman, dan jalan setapak sudah cukup indah, nyaman, dan aman. Dari hasil penilaian tersebut, area bermain merupakan area yang paling indah dan area yang paling nyaman sedangkan jalan setapak dan bangku taman merupakan area yang paling aman.

Pengunjung merasa puas dengan fasilitas yang terdapat di Taman Janggan terbukti dari $80 \%$ pengunjung merekomendasikan Taman Janggan kepada keluarga atau kerabat dekat mereka untuk sekedar jalan-jalan dan bermain. Frekuensi kunjungan pengunjung rata-rata tidak menentu dalam seminggu karena sebanyak $80 \%$ pengunjung yang datang berusia 17-35 tahun dengan latar belakang sebagai pekerja maupun pelajar yang hanya memiliki sedikit waktu senggang dan sebagian besar pengunjung memilih sore hari sebagai waktu yang tepat memanfaatkan waktu luang untuk mengunjungi Taman Janggan. Maka dari itu pengunjung secara umum dan pengelola secara khusus wajib menjaga segala fasilitas yang ada pada Taman Janggan agar tetap indah, nyaman, dan aman bagi siapapun yang akan berkunjung.

\section{Simpulan dan Saran \\ 4.1 Simpulan}

Secara umum persepsi pengunjung terhadap keindahan, kenyaman dan keamanan pada Taman Janggan jika dilihat dari hasil kuesioner dapat disimpulkan bahwa Taman Janggan sudah cukup indah, nyaman, dan aman. Mulai dari keindahan area playground, area gym, dan berbagai fasilitas lainnya, kenyamanan dengan material yang digunakan pada area playground, area gym, dan kenyamanan pada fasilitas lainnya seperti bangku taman dan jalan setapak yang ada pada Taman Janggan, serta keamanan bahan pada fasilitas yang ada dan keamanan barang bawaan pengunjung. Menurut persepsi pengunjung kebersihan dan pemeliharaan pada Taman Janggan masih kurang dan perlu mendapat pemeliharaan karena kebersihan juga mempengaruhi keindahan, kenyamanan, dan keamanan pengunjung.

\subsection{Saran}

Berdasarkan simpulan diatas, maka saran yang dapat diberikan untuk meningkatkan keindahan, kenyamanan, dan keamanan pengunjung adalah meningkatkan pengawasan, perawatan, dan kebersihan atau bahkan menambah fasilitas yang ada oleh pengelola agar Taman Janggan berfungsi dengan lebih maksimal.

\section{Daftar Pustaka}

Gie, T., L. (1983). Garis-garis Besar Estetik (Filsafat Keindahan). Yogyakarta, Supersukses.

Hakim, Rustam dan Hardi. (2003). Komponen Perancangan Arsitektur Lansekap Prinsip-Prinsip dan Aplikasi Disain. Jakarta: Bumi Aksara.

Kandir, T. (2017). Resmikan Taman Janggan, Wagub Bali Minta Warga Ikut Menjaga. Tribun Bali, 6 Januari 2017.

Pradipta, I., G., A. (2018). Persepsi Dan Preferensi Masyarakat Terhadap Taman Rekreasi Bantaran Sungai Loloan Sanur. Diunggah dari: https://ojs.unud.ac.id/index.php/lanskap/article/view/43438/26454. Diakses pada 18 Desember 2018

Sarsiti dan Taufiq. (2012). Penerapan Perlindungan Hukum terhadap Wisatawan yang Mengalami Kerugian di Obyek Wisata: Studi di Kabupaten Purbalingga. Purwokerto: Fakultas Hukum Universitas Jendral Soedirman Purwokerto. 
Satwiko, P. (2009). Pengertian Kenyamanan Dalam Suatu Bangunan. Yogyakarta: Wignjosoebroto. Silalahi, U. (2006). Metode Penelitian Sosial. Unpar Press. Bandung.

Sudiasa, D. (2018). Wawancara tentang "Studi Persepsi Pengunjung pada Taman Janggan Denpasar di Kantor Penataan Bangunan dan Lingkungan, 20 Februari 2018

Sugiyono. (2017). Metode Penelitian Kuantitatif, Kualitatif, dan R\&D. Bandung: Alfabeta 